\title{
A teoria de Galperin no processo de ensino da Educação Física: contribuições e aproximações
}

Galperin's theory in the physical education teaching process: contributions and approaches

La teoría de Galperin en el proceso de enseñanza de la educación física: contribuciones y enfoques

Rodrigo Souza Ramos ', Bruno Dandolini Colombo II, Vânia Vitório ${ }^{\mathrm{III}}$, Bruna Carolini De Bona ${ }^{\mathrm{IV}}$, Isabela Natal Milak ${ }^{\mathrm{V}}$

\section{Resumo}

Este artigo tem como pretensão relacionar a teoria de Galperin com a organização do ensino da Educação Física, de forma bibliográfica, explicando a formação de conceitos por meio das etapas de assimilação e dos princípios didáticos de Galperin. Para isso, dialogamos com a proposta teórico-metodológica da Educação Física CríticoSuperadora e a Teoria Histórico-Cultural. Concluímos que os conceitos se dão pela assimilação das etapas e princípios didáticos de Galperin, e a relação com a Educação Física acontece por dentro desse processo de ensino e aprendizagem.

Palavras-chave: Galperin; Educação Física; Ensino

\begin{abstract}
This article aims to relate Galperin's theory to the management of Physical Education teaching, by bibliographic way, explaining the formation of concepts through assimilation stages and the didactic principles by Galperin. To that end, we connect the theoretical-methodological proposal of Overcoming Critical Physical Education and the Historical-Cultural Theory. We conclude that the concepts occur through stages assimilation with didactic principles by Galperin, and the relationship with Physical Education happens within this process of teaching and learning.
\end{abstract}

Keywords: Galperin; Physical Education; Teaching

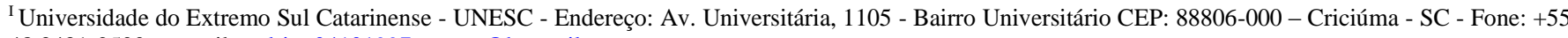
48 3431-2500 - e-mail: rodrigo04101997_ramos@hotmail.com

${ }^{\text {II } U n i v e r s i d a d e ~ d o ~ E x t r e m o ~ S u l ~ C a t a r i n e n s e ~-~ U N E S C ~ e-m a i l: ~ b r u n o @ u n e s c . n e t ~}$

III Universidade do Extremo Sul Catarinense - UNESC e-Mail: vvi@unesc.net

IV Universidade do Extremo Sul Catarinense - UNESC - e-mail: bcb@unesc.net

${ }^{v}$ Universidade do Extremo Sul Catarinense - UNESC - e-Mail: bela milak@ hotmail.com
} 


\section{Resumen}

Este artículo tiene como objetivo relacionar la teoría de Galperin con la organización de la enseñanza de la Educación Física, de manera bibliográfica, explicando la formación de conceptos a través de las etapas de asimilación y los principios didácticos de Galperin. Para ello, dialogamos con la propuesta teórico-metodológica Crítico Superadora de la Educación Física y la teoría Histórico-Cultural. Concluimos que los conceptos ocurren a través de la asimilación de las etapas y los principios didácticos de Galperin, y la relación con la Educación Física ocurre dentro de este proceso enseñanza y aprendizaje.

Palabras clave: Galperin; Educación Física; Enseñanza

\section{Introdução}

A partir de Vygotsky ${ }^{1}$ e Leontiev, Piotr Yakovlevich Galperin deu início a suas investigações (NUÑEZ, 2009). Foi por meio da teoria da atividade de Leontiev que desenvolveu sua teoria de formação de conceitos, a qual explica que:

A aprendizagem voltada para o desenvolvimento da personalidade integral dos alunos passa a ser compreendida como um tipo específico da atividade, com uma estrutura, que, do ponto de vista metodológico, potencializa a instrumentalização do ensino. (NÚÑ̃EZ, 2009, p. 18).

A teoria da atividade de Leontiev não esclarece o processo de internalização de fatores externos para a atividade mental. Esse foi o ponto-chave para Galperin e sua teoria de assimilação de conceitos (NÚÑEZ, 2009). Para Galperin, “a assimilação por etapas das ações mentais, explica o papel da atividade de orientação no processo de internalização da atividade externa para o plano mental, na qual, algumas compreensões vêm para nortear o processo de assimilação" (NÚÑEZ, 2009, p. 22).

A teoria de Galperin no processo de ensino da Educação Física foi o tema escolhido para realizar esta pesquisa. A opção por essa teoria se dá pela aproximação e relevância que apresenta à formação dos professores, pois traz uma concepção de ensino que "coloca no centro da atenção o processo de assimilação do aluno como elemento central da relação que se produz entre professor e aluno" (NÚÑEZ, 2009, p. 149). Galperin tem como base a Teoria Histórico-Cultural, vertente na qual a proposta metodológica de ensino Crítico-Superadora - referência teórica no campo da Educação Física - também se fundamenta. Nesse sentido, oferece um importante aporte a esta investigação.

\footnotetext{
${ }^{1}$ No decorrer do texto será utilizada a grafia Vygotsky ou Vigotski, conforme apresentadas nas obras referenciadas.
} 
A Educação Física é importante não apenas por integrar o currículo escolar da Educação Infantil ao Ensino Médio, mas por ser "uma prática pedagógica que, no âmbito escolar, tematiza formas de atividades expressivas corporais, como jogo, esporte, dança e ginástica, formas estas que configuram uma área de conhecimento que podemos chamar de cultura corporal” (COLETIVO DE AUTORES, 2012, p.50).

Portanto, esta pesquisa procura responder a seguinte problemática: como a formação de conceitos na teoria de Galperin pode contribuir para a organização de ensino da Educação Física? Nosso objetivo é compreender os processos de formação de conceitos segundo Galperin e sua contribuição para a organização do ensino da Educação Física. Como objetivos específicos, buscamos compreender os processos de formação de conceitos segundo Galperin, perceber suas contribuições ao ensino da Educação Física, e aproximar esses processos de formação de conceitos do ensino da Educação Física.

Uma das relevâncias deste estudo foi a participação dos autores deste artigo no Programa Institucional de Bolsas de Iniciação Científica (PIBIC), que contemplava a discussão sobre a teoria de Galperin, o que nos instigou a pesquisar acerca deste tema e a querer compreender e aprofundar a teoria de Galperin e sua contribuição para a disciplina de Educação Física, tendo em vista que durante a pesquisa não foram encontrados artigos, teses ou dissertações sobre esse tema voltados para esta área.

O estudo em evidência se caracteriza como uma pesquisa bibliográfica cujo foco é a análise da organização do ensino nos pressupostos de Galperin. Foram reunidos exemplares para coleta de informação a respeito de como isso se desenvolve, levando em consideração todo o processo de formação dessa teoria, ou seja, passando por dentro de outras teorias, de outros autores, que foram a "mola propulsora" para a concretização da teoria desenvolvida por Galperin. No campo da Educação Física, lançamos mão da obra Metodologia do ensino da Educação Física, elaborada pelo Coletivo de autores (1992).

Cabe destacar que, a partir dessa obra, em 1992, surge a proposta teórico-metodológica CríticoSuperadora, a qual se fundamenta na Teoria Histórico-Cultural. Dessa forma, a compreensão cada vez mais sofisticada dos princípios psicopedagógicos da perspectiva Histórico-Cultural contribui para a organização do ensino da Educação Física embasada numa proposta Crítico-Superadora (NASCIMENTO, 2014; EUZÉBIO, 2017; MILAK, 2018). 


\section{A teoria de Galperin}

A Educação Física é umas das disciplinas que constitui o currículo escolar do Ensino Infantil ao Ensino Médio. Possui como objeto de investigação a tematização de formas de atividades expressivas corporais, ou seja, a cultura corporal. Tem como conteúdo o jogo, o esporte, a capoeira, a ginástica e a dança, "visando apreender a expressão corporal como linguagem" (COLETIVO DE AUTORES, 2012, p. 62).

Como disciplina escolar, a Educação Física possui organizações didáticas e metodológicas que, desde seus primórdios, passaram por processos de mudança em suas concepções de ensino (COLETIVO DE AUTORES, 2012). Mas, direcionando para o que há de mais atual quando se trata de organização didático-metodológica de ensino, apontamos para a Teoria Histórico-Cultural. Porém, antes de abordar a teoria Histórico-Cultural, apresentaremos outras posições teóricas antecedentes que tratam da aprendizagem e do desenvolvimento.

Entendemos que a relação entre desenvolvimento e aprendizagem é uma questão central para a prática pedagógica, sobretudo porque nos remete às questões relacionadas a o que ensinar (os conteúdos), como ensinar (o modo de organizar o ensino) e porque ensinar (a finalidade da educação escolar) (ASBAHR; NASCIMENTO, 2013, p. 417, grifos dos autores).

No artigo "Criança não é Manga, não amadurece: o conceito de maturação na Teoria HistóricoCultural", as autoras Flávia da Silva Ferreira Asbahr e Carolina Picchetti Nascimento (2013) apontam que Vigotski divide as teorias que explicam o desenvolvimento e a aprendizagem em três categorias, sendo elas: a concepção inatista, a concepção empirista/ambientalista e a concepção dualista.

A concepção inatista defende que o desenvolvimento é um processo interno, que depende inteiramente da "maturação" do ser humano. A concepção empirista/ambientalista responsabiliza o meio em que o ser humano está inserido pelo seu desenvolvimento, ou seja, a primeira concepção explica que o desenvolvimento humano é biológico, já a segunda explica que o desenvolvimento humano acontece pela influência do meio físico e social (ASBAHR; NASCIMENTO, 2013). Essas concepções apresentam semelhanças, no sentido de não considerarem o processo de constituição de desenvolvimento histórico do ser humano. (ASBAHR; NASCIMENTO, 2013).

A terceira concepção, e não menos importante para compreendermos este percurso de aprendizado e desenvolvimento, é a concepção dualista. Esta considera o desenvolvimento e a aprendizagem de forma 
biológica, mas também considera o meio externo em que o ser humano está inserido, ou seja, faz uma junção das duas primeiras concepções (ASBAHR; NASCIMENTO, 2013).

\begin{abstract}
Segundo essas teorias, a aprendizagem é um processo puramente exterior, paralelo, de certa forma, ao processo de desenvolvimento da criança, mas que não participa ativamente neste e não o modifica absolutamente: a aprendizagem utiliza os resultados do desenvolvimento, em vez de se adiantar ao seu curso e de mudar a sua direção (VIGOTSKI, 1988, apud ASBAHR; NASCIMENTO, 2013, p. 417).
\end{abstract}

Para superar essas concepções de aprendizado e desenvolvimento, Vigotski busca, no materialismo histórico e dialético, a concepção que considera os processos históricos e constitui as bases da Teoria Histórico-Cultural (ASBAHR; NASCIMENTO, 2013). A Teoria Histórico-Cultural é uma concepção psicológica que busca compreender o ser humano em sua totalidade, naquilo que é, ou o que ele pode vir a ser, o considerando criador desta história, formador de cultura (ASBAHR; NASCIMENTO, 2013).

Ao postular a existência de uma linha biológica e de uma linha histórica no processo de desenvolvimento humano, Vigotski procura ressaltar os aspectos essenciais que fizeram e fazem o homem constituir um ser cultural, o que nos indica a possibilidade de intervenções conscientes no processo de formação de cada sujeito. Segundo o autor, as duas linhas entrelaçam-se dialeticamente no processo de desenvolvimento, formando uma unidade no processo de humanização, ou seja, o aspecto biológico é o ponto de partida do desenvolvimento humano, mas altera-se no decorrer do processo de apropriação da cultura pelo sujeito (ASBAHR; NASCIMENTO, 2013, p. 420).

Essas duas linhas de desenvolvimento devem ser compreendidas em unidade, em que a biológica estabelece as bases fisiológicas da existência, porém sofre mudanças conforme o sujeito se relaciona com o desenvolvimento social. Por meio das conquistas culturais, o ser humano transforma sua conduta. "Com essas formas culturais de conduta, o homem pôde criar seus órgãos artificiais (instrumentos e signos) e formar uma existência consciente ou uma existência para-si” (HELLER, 1997, apud ASBAHR; NASCIMENTO, 2013, p. 421). O entrelaçamento dessas duas linhas de desenvolvimento expressa o diferenciar-se dos animais, pois esta apropriação cultural é o mais alto nível de desenvolvimento humano (ASBAHR; NASCIMENTO, 2013).

A criação dos órgãos artificiais citados anteriormente, como instrumentos e signos, possibilita ao ser humano a criação de novas formas de organização do mundo, de interação com outros seres humanos e consigo mesmo. Esses órgãos artificiais expressam a interação com o mundo social e o trabalho, fazem 
com que as capacidades orgânicas evoluam, tornando-se aquilo que há de mais complexo e puramente humano, as funções psicológicas superiores (ASBAHR; NASCIMENTO, 2013).

Um dos principais livros utilizados nesta pesquisa foi Vygotsky, Leontiev, Galperin: Formação de conceitos e princípios didáticos. Nele propõe-se "a familiarização dos professores e estudiosos da aprendizagem com as ideias-chave da teoria de Galperin, como referencial para se pensar a aprendizagem e o ensino voltado para o desenvolvimento integral da personalidade dos alunos" (NÚÑEZ, 2009, p. 20). $\mathrm{O}$ autor considera que a escola faz uma leitura deturpada da aprendizagem, trazendo consequências avassaladoras para a educação dos alunos.

A escola que se educa muda a concepção dos processos de ensino e de aprendizagem. A educação se orienta ao desenvolvimento da personalidade integral do aluno, sendo o desenvolvimento não só um processo natural e sim um produto do acesso social e pedagogicamente organizado à cultura historicamente produzida (NÚÑEZ, 2009, p. 133).

Sendo assim, o desenvolvimento do aluno deve se orientar para a educação científica. "[...] a teoria de Galperin considera o estudo como um sistema de determinados tipos de atividades que levam ao aluno novos conhecimentos, habilidades, hábitos, atitudes, valores, sob um processo de direção" (NÚÑEZ, 2009, p. 92). Tal teoria aborda o processo de internalização das ações externas para ações mentais internas. Para poder compreender este processo, Galperin fez um estudo detalhado e defende que esse processo ocorre por etapas. Para o autor,

[...] o vínculo interno entre atividade e os novos conhecimentos e habilidades se dá quando, no processo da atividade, as ações isoladas se transformam em habilidades e, ao mesmo tempo, como consequência dessa atividade como os objetos, integram-se as representações e os conceitos a esses objetos. Por trás de cada imagem (e consequentemente dos conceitos), oculta-se uma ação mental generalizada, abreviada e automatizada (GALPERIN, 2001a, apud NUÑEZ, 2009, p. 94).

O centro da teoria de Galperin consiste em "primeiro, encontrar a forma adequada da ação; segundo, encontrar a forma material de representação da ação e, terceiro, transformar essa ação externa em interna" (NUÑEZ, 2009, p. 94). No sentido de formar uma nova ação, ao passar por esses três momentos, sua forma é primeiro material, em seguida verbal, e por fim mental, desenvolvendo assim suas funções psicológicas superiores (NUÑEZ, 2009).

Dessa forma, prestam-se as ajudas necessárias aos alunos durante o processo de formação de conceitos. O processo de aprendizagem, como processo de assimilação dos conteúdos, avança do geral para o concreto, por meio da atividade conjunta e por mecanismos de 
simbolização do conteúdo, usando a linguagem como meio de formulação linguística de relação e de conscientização do aluno (NUÑEZ, 2009, p. 94-95).

Conforme mencionado anteriormente, Galperin aborda em seu estudo as etapas necessárias para promover a assimilação. São elas: a) A etapa motivacional, que visa incentivar o aluno à atividade de estudo, de modo que busque motivações internas, no sentido de estudar por ter vontade de conhecer, de adquirir novos saberes. Nesse processo o professor também é responsável por criar motivos que incentivem o aluno à atividade de estudo. b) A etapa de estabelecimento da Base Orientadora da Ação (BOA), que dará subsídios para o tipo de atividade a ser desenvolvida pelo o aluno.

Essa etapa deve ser estabelecida num processo de elaboração do conhecimento de tal modo que os alunos possam construir, junto com o professor, num processo de elaboração conjunta, o modelo da atividade que realizarão (a habilidade em formação) (NUÑEZ, 2009, p. 101).

c) A etapa de formação da ação no plano material ou materializado, que explica o objeto de estudo nessas duas perspectivas: no plano material o objeto de estudo é o próprio objeto; no plano materializado é uma forma de representar este objeto de estudo de outra maneira, mas que contenha os elementos primordiais do objeto de estudo em questão.

Os elementos essenciais na ilustração devem ser fixados para não distrair a atenção dos alunos em aspectos não essenciais, ou seja, a forma gráfica, ilustrativa, deve representar somente a que reflete a essência do conteúdo e da atividade ou da ação que deve realizar, levando em consideração a idade do aluno e sua experiência com o conteúdo (NUÑEZ, 2009, p. 107).

d) A etapa de formação de ação no plano da linguagem externa, que por sua vez destaca a importância da linguagem como um agente que permite ao ser humano se expressar de diferentes formas, estabelecendo relações, formando conceitos, comunicando e resolvendo atividades propostas a ele (NUÑEZ, 2009). e) A última etapa de assimilação na teoria de Galperin, segundo Nuñez (2009), é a etapa mental, parte final do processo de assimilação. Nela o ser humano passa do processo da linguagem externa para a reflexão. "Na etapa mental, a linguagem interna (nova estrutura psicológica) se transforma 
em função mental interna e proporciona ao aluno novos meios para o pensamento" (NUÑEZ, 2009, p. 114).

Essas etapas servem para organizar o processo de ensino. Nelas os alunos desenvolvem habilidades. É o processo da assimilação, por meio do qual os alunos passam do plano externo ao plano mental interno (NUÑEZ, 2009).

A passagem pelas etapas de assimilação de um conceito, como um tipo específico de atividade explicada pela teoria de Galperin, que se orienta não somente para a definição do conceito, mas também para a sua aplicação, obrigando, portanto, a trabalhar as características essenciais do conceito, é uma via para a formação de abstrações e generalização, sob a forma de conceitos científicos. O aluno, portanto, centra sua atenção no próprio ato de pensar durante o processo de formação de conceito (NUÑEZ, 2009, p. 116).

As etapas acontecem de forma dialética, no sentido de que a passagem de uma para a outra não desconsidera a anterior, todas as etapas são partes de um todo, com o objetivo de fazer com que o aluno obtenha mais sucesso em sua atividade de estudo (NUÑEZ, 2009).

\section{Proposta teórico-metodológica Crítico Superadora}

O objetivo do estudo é compreender os processos de formação de conceitos segundo Galperin e sua contribuição para o ensino da Educação Física. Para isso, voltamo-nos para os processos metodológicos que subsidiam o ensino da Educação Física. Ou seja, adotamos como referência o livro Metodologia de Ensino da Educação Física, do Coletivo de Autores (1992).

Os critérios utilizados para a escolha da obra como porta-voz do ensino da Educação Física levaram em conta o fato de ser uma das metodologias de ensino mais contemporâneas e, também, de sua vertente ser a mesma que dá subsídios para a teoria de Galperin: a Teoria Histórico-Cultural. A Educação Física, nos processos de ensino, tem uma longa história, permeada por várias propostas. Mas o Coletivo de Autores (2012) traz como elo de ligação com a teoria de Galperin a concepção Histórico-Cultural. O coletivo de Autores avalia que esta concepção se difere das tendências anteriores, uma vez que "busca desenvolver uma reflexão pedagógica sobre o acervo de formas de representação do mundo que o homem tem produzido no decorrer da história” (COLETIVO DE AUTORES, 2012, p. 39). 
O livro mencionado traz como orientação na organização de ensino os chamados princípios curriculares para organizar e sistematizar os conteúdos do ensino. "Pode-se dizer que os conteúdos de ensino emergem de conteúdos culturais universais, construindo-se em domínio de conhecimento relativamente autônomos, incorporados pela humanidade e reavaliados, permanentemente, em face da realidade social” (LIBÂNEO, 1985, apud COLETIVO DE AUTORES, 2012, p. 32).

Os princípios curriculares de seleção dos conteúdos são:1) A relevância social do conteúdo, que destaca a importância de relacioná-lo à explicação da realidade social concreta, o que possibilita ao aluno compreender os determinantes sócio-históricos e sua condição de classe social; 2) A contemporaneidade do conteúdo, que significa que o conteúdo selecionado deve abordar o que há mais contemporâneo sobre o assunto; 3) A adequação às possibilidades sociocognoscitivas do aluno, que implica adequar o conteúdo à capacidade cognitiva e à prática social do aluno como sujeito histórico (COLETIVO DE AUTORES, 2012).

Com relação à organização e à sistematização do conteúdo, temos os seguintes princípios: 1) Confronto e contraposição de saberes: esclarece que o conhecimento científico é a resposta para saberes de senso comum que os alunos trazem do seu meio social; 2) Simultaneidade dos conteúdos enquanto dados da realidade: propõe que o conteúdo não seja tratado em etapas, mas abordado de uma forma contínua, sem divisões por anos; 3) Espiralidade da incorporação das referências do pensamento: vincula-se à compreensão das diferentes formas de organizar as referências do pensamento sobre o conhecimento e ampliá-las; 4) Provisoriedade do conhecimento: explicita que os conteúdos são conhecimentos que adentram a história, que ele próprio, o aluno, é sujeito dessa história, e que o conhecimento pode ser compreendido como algo constantemente modificado nesse processo.

Porém, organizar o ensino, segundo o Coletivo de Autores (1992), é também considerar que não devemos pensá-lo em etapas, mas considerá-lo em ciclos de escolarização. Nesses ciclos,

[...] os conteúdos de ensino são tratados simultaneamente, constituindo-se referências que vão se ampliando no pensamento do aluno de forma espiralada, desde o momento da constatação de um ou vários dados da realidade, até interpretá-los, compreendê-los e explicá-los (COLETIVO DE AUTORES, 2012, p. 36).

Os autores apontam quatro ciclos de escolarização, quais sejam: $1^{\circ}$ ) ciclo da organização da identidade dos dados da realidade, que se estende pré-escola até o $4^{\circ}$ ano, em que o aluno tem o primeiro contato com o ensino específico de algum conteúdo; $2^{\circ}$ ) ciclo de iniciação à sistematização do 
conhecimento, que vai do $5^{\circ}$ ao $7^{\circ}$ ano, em que o aluno começa a fazer referências fundamentadas, amplia seu pensamento; $3^{\circ}$ ) ciclo de ampliação da sistematização do conhecimento, que compreende o $8^{\circ}$ e o $9^{\circ}$ anos, em que o aluno vai tomar consciência da atividade teórica, ampliando sua capacidade mental; $4^{\circ}$ ) ciclo de aprofundamento da sistematização do conhecimento, que acontece nos três anos do Ensino Médio, no qual o aluno se depara com os conceitos científicos e, nessa relação, pode vir a ser produtor de conhecimento (COLETIVO DE AUTORES, 2012).

De acordo com os autores, o professor de Educação Física assume a responsabilidade de tratar seu objeto de estudo com muita maestria, no sentido de superar os processos de ensino e aprendizagem tradicionais. O Coletivo de Autores (2012) explicita esse compromisso quando apresenta toda essa preocupação com o ensino da Educação Física, por assumir um objeto de estudo próprio, a cultura corporal, tematizada por meio de atividades corporais como: jogo, esporte, dança, lutas, sob as referências da Teoria Histórico-Cultural.

\section{Contribuições da teoria de Galperin para a Educação Física}

Para compreender as contribuições da teoria de Galperin e relacioná-las com a Educação Física, é necessário entender os princípios didáticos desta teoria. Tais princípios surgem como fundamentos para a organização e aplicação do processo de ensino e derivam da teoria de assimilação de Galperin. Na sequência os explicitaremos utilizando-nos da síntese elaborada por Núñez (2009).

- Princípio do caráter educativo de ensino: afirma que o professor, assim como a escola, deve garantir a formação integral do aluno no seu aspecto cognoscitivo, mas também no seu aspecto afetivo.

- Princípio do caráter científico do ensino: explica que o processo educativo aponta para o desenvolvimento científico e atual na sociedade,

[...] na qual ele é uma ferramenta da cidadania, exige um pensamento do tipo teórico, que permita transcender do aparente, do fenomenológico, e penetrar na natureza interna dos objetos e fenômenos da realidade (sua essência) (NUÑEZ, 2009, p. 134).

Ou seja, este princípio permite levar o aluno de um pensamento abstrato ao concreto. 
- Princípio do ensino que desenvolve: explicita que o ensino e a aprendizagem dão subsídios para promover o desenvolvimento integral do aluno. Considera não apenas o conhecimento adquirido pelo aluno durante um período de tempo, mas também o potencial de vir a desenvolver este conhecimento. Essa potencialidade de vir a desenvolver o conhecimento é caracterizada como Zona de Desenvolvimento Proximal. Cabe ao professor e à escola criarem estímulos para o desenvolvimento do aluno, ajudando-o a avançar sobre determinado conhecimento de forma qualitativa.

- Princípio do caráter consciente: considera que "a aprendizagem como um tipo específico da atividade por meio da qual os alunos se apropriam dos conteúdos deve ser um processo consciente" (NUÑEZ, 2009, p. 138), ou seja, uma forma de reflexão para poder organizar as estratégias aprendizagem.

- Princípio do caráter objetal: orienta para a

[...] identificação das ações específicas que necessitam serem realizadas com os objetos da assimilação para revelar o conteúdo do conceito em estudo e para representar o conteúdo primário em forma de modelos conhecidos (do tipo material, gráfico ou verbal) (NUÑEZ, 2009, p. 139).

- Princípio da definição ou formulação exata e clara dos objetivos: afirma que o professor deve ter clareza dos objetivos a serem desenvolvidos, pois estão entrelaçados com a atividade de ensino.

- Princípio do caráter seletivo de percepção: explicita que a percepção do aluno é estimulada pelo professor mediante uma explicação, pois existem vários fatores psicológicos que atrapalham esta percepção.

- Princípio do caráter ativo da assimilação: esclarece que o ser humano não consegue assimilar o objeto quando não tem interação com ele, ou seja, o processo de ensino e aprendizagem deve ser um processo ativo, no qual "o caráter ativo do processo de assimilação exige do ensino a busca pelo tipo mais produtivo de atividade para atingir os objetivos" (NUÑEZ, 2009, p. 141).

- Princípio da vinculação da aprendizagem com a vida: destaca que os conteúdos devem ter relação com os acontecimentos da sociedade atual. A escola deve levar em consideração a experiência dos alunos, para que os eles não esqueçam este conhecimento. Para isso acontecer, a escola deve vincular o conteúdo com as experiências dos alunos.

- Princípio da ilustratividade e da materialização: 
Serve para orientar a etapa da base orientadora da ação. Nessa etapa, devem ser representados não só os objetos com os quais se atua, mas também representar de forma externa o conteúdo da orientação para a execução da atividade (a estrutura da atividade) (NUÑEZ, 2009, p. 143).

- Princípio da unidade entre o ilustrativo e o verbal: busca garantira passagem do plano ilustrativo para o plano verbal, no qual as palavras tomam sentido subsidiando o objeto representado.

- Princípio da retroalimentação: aborda a questão de identificar o "ritmo" em que os alunos estão sobre um determinado assunto, pois o professor pode localizar o erro e explicar novamente o assunto. Neste princípio, o erro é considerado parte do processo de aprendizagem. "Os alunos trabalham com apoio externo e em interação comunicativa com os colegas e o professor, de forma que se possam detectar a tempo as dificuldades e se possam fazer os ajustes e correções necessárias" (NUÑEZ, 2009, p. 144).

- Princípio do caráter sistêmico do objeto da assimilação: ressalta que

[...] o conteúdo da aprendizagem não deve ser estruturado casualmente, fragmentado, e sim com uma nova lógica de estruturação. O conteúdo deve se estruturar sobre núcleos invariantes de conhecimento essenciais e gerais (NUÑEZ, 2009, p. 145).

- Princípio da sistematização do ensino: salienta que a aprendizagem é um processo que requer que os conteúdos sejam sistematizados pela passagem de tarefas/atividades. "São tarefas orientadas, que permitam a formação das habilidades e hábitos seguindo os parâmetros qualitativos das atividades definidas nos objetos" (NUNÑEZ, 2009, p. 145). O conhecimento está dentro de um sistema que tem uma ordem, porém não determina uma sistematização linear, pois assim você pode estabelecer relações diversas.

- Princípio da aprendizagem criativa: último princípio didático e não menos importante, compreende que a criação pelos alunos consiste em criarem formas, estratégias e táticas para a resolução de problemas com base nos conteúdos assimilados. Esse processo de assimilação das habilidades

[...] é um processo que se orienta não só para a capacidade dos alunos para explicarem, compreenderem e fazerem novas leituras da realidade, como também para a apropriação de novas vias de transformação dessa realidade (NUÑEZ, 2009, p. 147). 
$\mathrm{Na}$ organização metodológica do ensino, os princípios didáticos apontam algumas transformações. O processo de ensino deve abordar a definição dos objetivos e o professor tem que ter clareza disso no processo de ensino e aprendizagem, além de ter definido seu objetivo, pois ele influencia diretamente nos processos de determinado conteúdo abordado. É importante ressaltar que o processo de ensino da teoria de Galperin, segundo Nuñez (2009), traz o diagnóstico como um processo de identificação das habilidades e conhecimentos que o aluno possui, ou seja, o conhecimento prévio.

A estruturação dos conteúdos está ligada diretamente ao objeto de estudo específico de cada disciplina e em como o professor vai abordar os conceitos básicos deste objeto de investigação. Apenas passar esse conteúdo verbalmente é insuficiente para que o aluno possa internalizar esse conceito, uma vez que "as investigações têm demonstrado que as informações factuais e conceituais, memorizadas durante o curso tradicional, têm pouca consistência” (NUÑEZ, 2009, p. 169).

Nos tópicos anteriores procuramos explicitar que a teoria de Galperin, além de explicar o processo de internalização por meio das etapas de assimilação, esclarece o processo didático e como executá-lo de forma prática. Esses dois quesitos vão se interpelar com a Educação Física no quesito ensino e aprendizagem, no sentido de unificar a proposta metodológica de ensino trazida no tópico3 deste artigo com a teoria de Galperin.

Os princípios didáticos de Galperin, abordados por Nuñez (2009), podem ser relacionados aos princípios do trato do conhecimento da proposta metodológica de ensino Crítico-Superadora, pois estes dão subsídios para a organização e direção de um ensino de qualidade, visando o conhecimento científico teórico, de forma a superar paradigmas, levando o aluno a um poder de reflexão e de desenvolvimento, ou seja, promovendo suas funções psicológicas especificamente humanas.

Essa junção da teoria de Galperin com a proposta metodológica de ensino Crítico-Superadora tende a potencializar o ensino no intuito da formação dos alunos como foco central, fazendo com que melhorem de forma qualitativa no sentido de compreender melhor determinado conteúdo, dando-lhes, assim, mais autonomia no confronto com a realidade social e natural.

\section{Conclusões}

O presente estudo fez com que compreendêssemos que a teoria de Galperin verte de questões que a teoria de Leontiev não explica, sobretudo a passagem da atividade externa para atividade interna. 
Notamos também que a teoria de Galperin tem base na Teoria Histórico-Cultural para explicar alguns fatores, os quais se relacionam com o desenvolvimento integral do ser humano.

A partir da exposição teórica e movidos pela problemática de como a formação de conceitos na teoria de Galperin pode contribuir para o Ensino da Educação Física, obtivemos uma compreensão deque a teoria de Galperin pode auxiliar na organização do ensino da Educação Física de forma qualitativa. Esta pode ser potencializada se considerarmos que a metodologia de ensino da Educação Física CríticoSuperadora se relaciona com a teoria de Galperin em dois elos. O primeiro é a relação comum de suas bases, a Teoria Histórico-Cultural. O segundo elo é a semelhança no que diz respeito aos princípios didáticos com os princípios curriculares do trato do conhecimento, ou seja, esses princípios se relacionam, no sentido de apontar a direção para uma organização didático-metodológica pautada em uma organização de ensino que gere desenvolvimento dos alunos.

E como resposta ao objetivo do estudo, compreender os processos de formação de conceitos segundo Galperin e sua contribuição para o ensino da Educação Física, entendemos que os processos de formação de conceitos podem ser compreendidos na passagem das etapas de assimilação e pelos processos didáticos de Galperin, levando o aluno à assimilação do conceito, fazendo com que ele internalize, ou seja, transforme a atividade externa em atividade interna.

Tal artigo foi desenvolvido bibliograficamente, porém necessitamos ainda aprofundar os debates aqui expostos no sentido de conduzira relação da teoria de Galperin com o ensino da Educação Física para uma pesquisa de cunho experimental nas aulas de Educação Física.

\section{Referências}

ASBAHR, Flávia da Silva Ferreira, NASCIMENTO, Carolina Picchetti. Criança não é Manga, não amadurece: conceito de maturação na Teoria Histórico-Cultural. Psicologia: Ciência e Profissão, vol. 33, n. 2, p. 414-427, 2013.

COLETIVO DE AUTORES. Metodologia do Ensino de Educação Física. São Paulo: Cortez, 2012.

EUZÉBIO, C. A. O conteúdo teórico dos conceitos de tática e estratégia no esporte.2017. Tese (doutorado) - Universidade Federal de Santa Catarina, Centro de Ciências da Educação, Programa de PósGraduação em Educação, Florianópolis, 2017.

MILAK, I. N. O ensino do jogo na perspectiva davydoviana. 2018. Dissertação (Mestrado em Educação) - Programa de Pós-Graduação em Educação da Universidade do Extremo Sul Catarinense, Criciúma, 2018. 
NASCIMENTO, C, P. A atividade pedagógica da Educação Física: a proposição dos objetos de ensino e o desenvolvimento das atividades da cultura corporal. 2014. Tese (Doutorado em Educação) Programa de Pós-Graduação em Educação, Faculdade de Educação da Universidade de São Paulo, São Paulo, 2014.

NÚÑEZ, Isauro Beltrán. Vygotsky, Leontiev e Galperin: formação de conceitos e princípios didáticos. Brasília: Liber livros, 2009.

\section{Como citar este artigo:}

RAMOS, R. S. R.; COLOMBO, B. D.; VITÓRIO, V.; BONA, B. C.; MILAK, I. N. A teoria de Galperin no processo de ensino da Educação Física: contribuições e aproximações. Revista Kinesis, Santa Maria, v.39, p. 1-14, 2021.

* O presente trabalho não contou com apoio financeiro de nenhuma natureza para sua realização. 